\title{
Alternatif Perencanaan Timbunan Jalan dengan Material Sirtu dan Material Ringan Mortar Busa pada Jalan Tol Batang - Semarang Seksi III Weleri - Kendal STA 414+525 - STA 424+576
}

\author{
Moch. Alfian Putra Adi, Yudhi Lastiasih, dan Indrasurya B. Mochtar \\ Departemen Teknik Sipil, Institut Teknologi Sepuluh Nopember (ITS) \\ Corresponding Author: indrasurya@ce.its.ac.id
}

\section{ARTIKEL INFO}

\section{Informasi Artikel}

Artikel masuk :

Artikel revisi :

Artikel diterima :

\begin{abstract}
ABSTRAK
Jalan Tol Batang - Semarang merupakan bagian dari proyek Jalan Tol Trans Jawa. Jalan Tol Trans Jawa adalah jaringan jalan tol antar kota di Pulau Jawa dengan tujuan utamanya untuk menghubungkan wilayah di Pulau Jawa, yaitu dari Kota Jakarta sampai Kota Surabaya, dan rencana akan dilanjutkan hingga Kabupaten Banyuwangi. Proyek Jalan Tol Batang - Semarang direncanakan memiliki panjang total $\pm 75 \mathrm{~km}$ terbagi dalam 3 seksi. Jalan tol ini rencananya akan dibangun di atas timbunan dengan elevasi yang relatif tinggi yaitu 3-meter s/d 12-meter pada STA 414+525 - STA 424+576. Kondisi tanah dasarnya adalah tanah lunak hingga medium yang memilki kedalaman \pm 10 meter dengan nilai N-SPT rata - rata berkisar 5 s.d. 12 sehingga memiliki daya dukung yang rendah dan pemampatan tanah yang relatif besar. Oleh karena itu, perlu adanya desain perencanaan konstruksi timbunan jalan dari material yang aman dan cukup ringan agar pemampatan tanah dasar yang terjadi dapat diminimalisir. Diperlukan juga perencanaan perbaikan tanah dasar dan perencanaan perkuatan timbunan agar timbunan menjadi lebih stabil. Perencanaan timbunan jalan dilakukan dengan menggunakan 2 (dua) material yang berbeda, yaitu material tanah sirtu dan material ringan mortar busa sebagai material timbunan. Metode perbaikan tanah dasar direncanakan menggunakan metode pra - pembebanan (pre-loading) yang dikombinasikan dengan Prefabricated Vertical Drain (PVD) kedalaman penuh sedalam tanah lunak dan vacuum pre-loading direncanakan untuk perbaikan tanah dasar dibantu dengan pompa untuk mengangkat air dari dalam lapisan tanah dasar. Hasil analisa, perencanaan timbunan dengan material mortar busa memiliki nilai pemampatan tanah yang lebih kecil daripada perencanaan timbunan dengan material tanah sirtu. $P V D$ yang digunakan memakai pola segitiga dengan jarak $1 \mathrm{~m}$ dan 1,2 m. Selain itu, perencanaan timbunan dengan material mortar busa jauh lebih stabil sehingga tidak membutuhkan perkuatan, sedangkan untuk perencanaan timbunan dengan material tanah sirtu membutuhkan perkuatan geotextile un-woven sebanyak $4-43$ lapis untuk tinggi timbunan rencana $11,5 \mathrm{~m}$ dan untuk timbunan rencana $3,1 \mathrm{~m}$ tidak memerlukan geotextile sebagai perkuatan. Total biaya material perencanaan untuk variasi timbunan dengan material mortar busa jauh lebih besar daripada total biaya material perencanaan untuk timbunan tanah sirtu.
\end{abstract}

\section{PENDAHULUAN}

Pemerintah merencanakan pembangunan infrastruktur transportasi Jalan Tol Trans Jawa yang menghubungkan kota dan kabupaten yang ada di Pulau Jawa didasari akan pentingnya infrastruktur bagi pertumbuhan bangsa Indonesia. Rencana Jalan Tol Trans Jawa yang menghubungkan kota dan kabupaten di Pulau Jawa.
Dengan adanya jalan bebas hambatan ini bertujuan untuk meningkatkan perekonomian daerah serta mendukung mobilitas dan aksesibilitas jalur darat di Pulau Jawa.

Pada bahasan kali ini adalah Jalan Tol Batang Semarang seksi III Weleri - Kendal STA 414+525 - STA 424+576 dengan memperhatikan lokasi proyek yang dibangun di atas tanah yang bervariasi, beberapa titik 


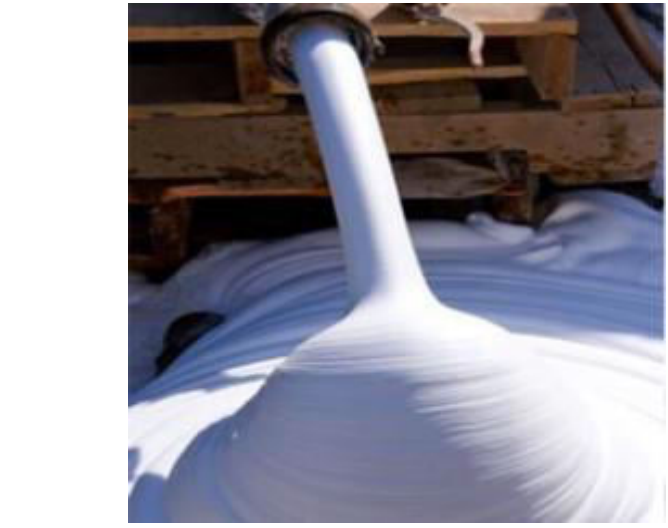

Gambar 1. Foam Mortar Busa.

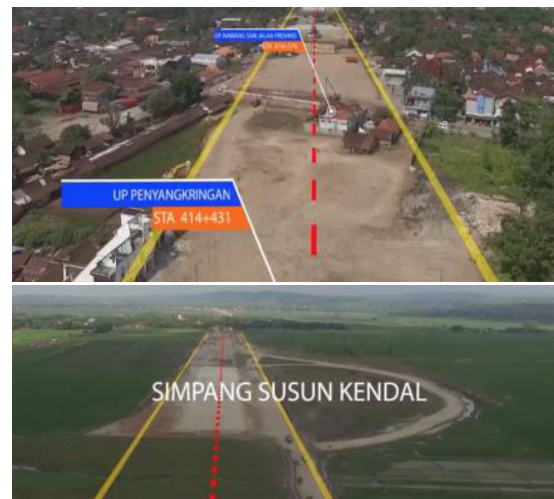

Gambar 2. Lokasi Lokasi Proyek Timbunan Jalan Tol STA 414+525 dan STA 424+576

(Sumber: PT. Waskita Karya)

terdapat tanah lunak dengan nilai rata rata $\mathrm{N}$ SPT dibawah sepuluh dengan ketebalan tanah lunak yang bervariasi antara 4 meter sampai dengan 10 meter. Oleh karena itu perlu diwaspadai stabilitas timbunan dengan adanya potensi terjadi pemampatan yang besar dan longsor saat dilakukan penimbunan.

Maka dalam hal ini akan direncanakan dan dibandingkan stabilitas timbunan menggunakan material biasa dengan material ringan yaitu mortar busa (Gambar 1) yang diperkuat dengan geotextile. Diambil STA 414+525 dan STA 424+576 karena dapat mewakili perencanaan timbunan Jalan Tol Batang - Semarang.

Untuk perbaikan tanah dasar menggunakan perbandingan antara vacuum pre-loading dan PVD (prefabricated vertical drain), Hasil dari beberapa metode ini akan dipilih yang paling optimum dari segi biaya material untuk pembangunan Jalan Tol Batang Semarang seksi III Weleri - Kendal STA 414+525 - STA 424+576. (Gambar 2)

\section{METODE PENELITIAN}

Metodologi yang digunakan dalam penyusunan Studi ini dapat dilihat pada Gambar 3.

\section{HASIL DAN PEMBAHASAN}

\section{A. Analisis Data Perencanaan}

1. Data Tanah (Gambr 4)

Nilai parameter data tanah didapatkan dari rumus empiris dan menggunakan grafik korelasi [1][2]. (Tabel 1)

2. Data Timbunan

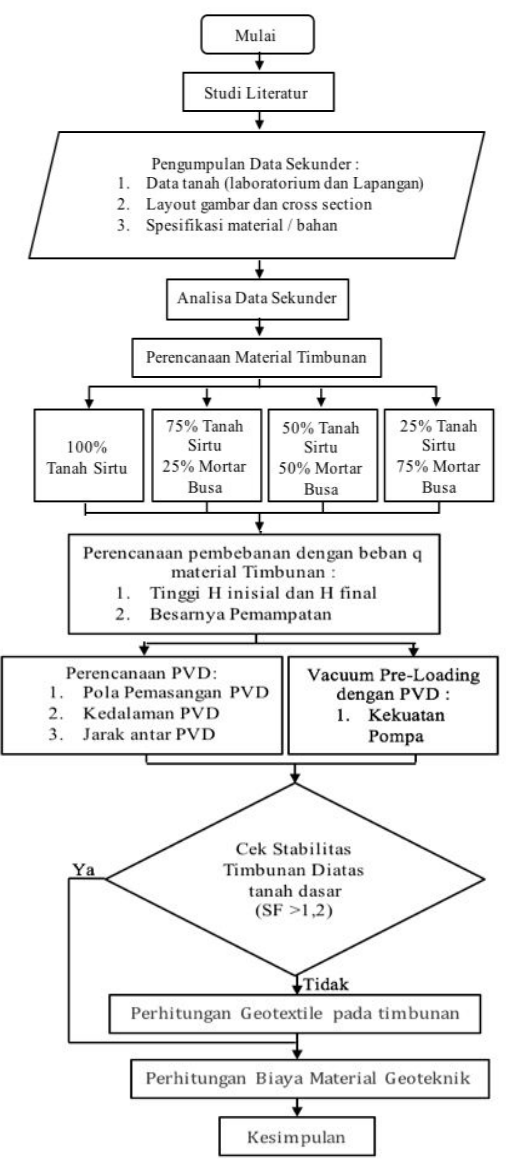

Gambar 3. Bagan alir studi.

Spesifikasi material timbunan mortar busa didapatkan dari sumber Kajian Penanganan Tanah Lunak Dengan Timbunan Jalan Mortar Busa [3]. (Tabel 2 dan Gambar 2)

Direncanakan untuk timbunan mortar busa menggunakan base setinggi $20 \mathrm{~cm}$ dan subbase mengikuti desain rencana variasi timbunan.

3. Data Beban

Rekapitulasi Pembebanan Pada Timbunan Tanah Sirtu STA 414+525 dapat dilihat pada Tabel 3.

4. Data Spesifikasi Bahan

Geotextile yang akan digunakan dalam perencanaan ini adalah tipe Polypropylene un-Woven Geotextile UW250 dengan kekuatan $52 \mathrm{kN} / \mathrm{m}$. Pre-fabricated vertical drain (PVD) yang akan digunakan dalam perencanaan ini adalah tipe CeTeau Drain CT-D822 produksi dari PT. Teknindo Geosistem Unggul. Pre-fabricated horizontal drain (PHD) CeTeau Drain CT-SD100-20 Distributor: PT. Teknindo Geosistem Unggul. Pompa Vacuum Preloading 7.5kW 10 HP High Capacity Double Suction, produsen Modo Pump Co., Ltd

\section{B. Perencanaan Geoteknik}

1. Perhitungan Besar Pemampatan Tanah (Sc), Tinggi Timbunan Awal $\left(\mathrm{H}_{\text {initial }}\right)$, dan Tinggi Timbunan Akhir $\left(\mathrm{H}_{\text {final }}\right)$ Pada Timbunan Tanah Sirtu STA414+525. Perhitungan preloading akibat variasi beban q (Noor Endah, 2012). Didapatkan hubungan antara $\mathrm{H}_{\text {final }}$ dengan $\mathrm{Sc}$,dan $\mathrm{H}_{\text {final }}$ dengan $\mathrm{H}_{\text {inisial }}$ (Gambar 6) dan (Gambar 7). (Tabel 4)

2. Perhitungan tinggi timbunan awal $\left(\mathrm{H}_{\text {initial }}\right)$ dan Tinggi timbunan Akhir $\left(\mathrm{H}_{\text {final }}\right)$ Pada Timbunan 50\% Mortar Busa 50\% Tanah Sirtu. (Tabel 5 dan 6) (Gambar 8) 
3. Perhitungan Waktu Pemampatan Tanah Dasar Tanpa PVD (Tabel 7)

4. Perencanaan Prefabricated Vertical Drain (PVD) dan Penimbunan Bertahap.

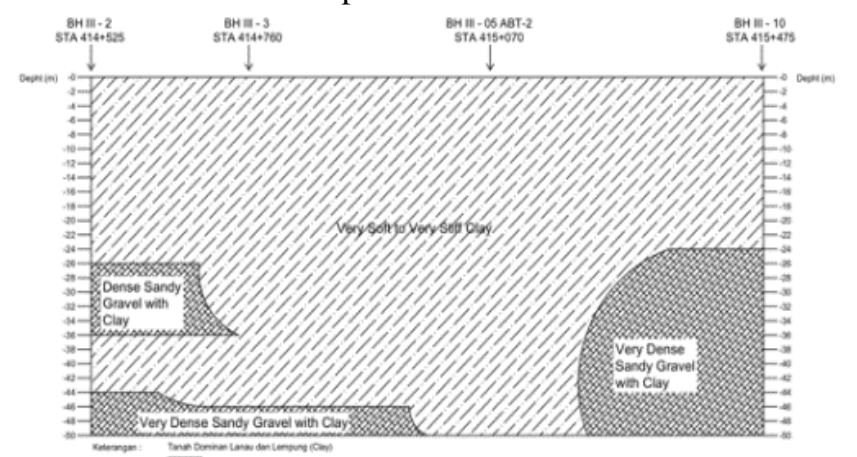

Gambar 4. Sketsa Gambar Data Stratigrafi Tanah STA $414+525$ - STA $415+475$.

Tabel 1. Parameter Data Tanah pada STA 414+525 (a) Data Tanah Volumetric dan Gravimetric (b) Data Tanah Consolidation (c) Data Tanah Kekuatan Tanah dan Atterberg Limits

\begin{tabular}{|c|c|c|c|c|c|c|c|c|}
\hline \multirow[b]{2}{*}{ DEPTH } & \multirow{2}{*}{$\begin{array}{l}\text { N- } \\
\text { SPT }\end{array}$} & \multirow[b]{2}{*}{$\mathrm{N}^{\prime}$} & \multirow[b]{2}{*}{$\mathrm{N}^{\prime}$} & \multirow{2}{*}{$\begin{array}{c}\text { Type of } \\
\text { Soil }\end{array}$} & \multicolumn{4}{|c|}{ Volumetric + Gravimetric } \\
\hline & & & & & $\mathrm{n}$ & e & $\begin{array}{c}\gamma \text { dry } \\
(\mathrm{t} / \mathrm{m} 3)\end{array}$ & $\begin{array}{c}\gamma \mathrm{sat} \\
\left(\mathrm{kN} / \mathrm{m}^{3}\right)\end{array}$ \\
\hline 0 & 0 & 0 & 0 & Soft & $*$ & $*$ & $*$ & $*$ \\
\hline 2 & 4 & 4 & 4 & Clay & 0,70 & 2,38 & 0,80 & 1,50 \\
\hline 4 & 6 & 6 & 6 & \multirow{5}{*}{$\begin{array}{c}\text { Medium } \\
\text { Clay }\end{array}$} & 0,68 & 2,16 & 0,86 & 1,54 \\
\hline 6 & 9 & 9 & 9 & & 0,64 & 1,75 & 1,00 & 1,62 \\
\hline 8 & 8 & 8 & 8 & & 0,66 & 1,90 & 0,93 & 1,59 \\
\hline 10 & 9 & 9 & 9 & & 0,64 & 1,75 & 0,98 & 1,62 \\
\hline 12 & 9 & 9 & 9 & & 0,64 & 1,75 & 0,98 & 1,62 \\
\hline
\end{tabular}

\begin{tabular}{ccccccc}
\hline \multicolumn{1}{c}{ (a) } \\
DEPTH & \multirow{2}{*}{ N-SPT } & \multirow{2}{*}{$\mathrm{N}^{\prime}$} & N' & \multicolumn{4}{c}{ Consolidation } \\
& & & $\mathrm{Cs}$ & $\mathrm{Cc}$ & $\mathrm{Cv}\left(\mathrm{cm}^{2} / \mathrm{s}\right)$ \\
\hline 0 & 0 & 0 & 0 & $*$ & $*$ & $*$ \\
2 & 4 & 4 & 4 & 0,127 & 0,633 & 0,000200 \\
4 & 6 & 6 & 6 & 0,113 & 0,567 & 0,000257 \\
6 & 9 & 9 & 9 & 0,089 & 0,444 & 0,000500 \\
8 & 8 & 8 & 8 & 0,098 & 0,489 & 0,000370 \\
10 & 9 & 9 & 9 & 0,089 & 0,444 & 0,000470 \\
12 & 9 & 9 & 9 & 0,089 & 0,444 & 0,000470 \\
\hline
\end{tabular}

\begin{tabular}{|c|c|c|c|c|c|c|c|c|c|}
\hline \multirow[b]{2}{*}{$\begin{array}{c}\text { DEP } \\
\text { TH }\end{array}$} & \multirow[b]{2}{*}{$\begin{array}{l}\text { N- } \\
\text { SPT }\end{array}$} & \multirow[b]{2}{*}{$\begin{array}{l}\mathrm{N} \\
,\end{array}$} & \multirow[b]{2}{*}{$\stackrel{N}{,}$} & \multicolumn{3}{|c|}{ Strength } & \multicolumn{3}{|c|}{ Atterberg Limits } \\
\hline & & & & $\Phi$ & $\begin{array}{c}C^{\prime} \\
(\mathrm{Kpa})\end{array}$ & $\begin{array}{c}\mathrm{Cu} \\
(\mathrm{Kp} \\
\mathrm{a})\end{array}$ & $\begin{array}{l}\mathrm{LL} \\
(\%)\end{array}$ & $\begin{array}{l}\text { PI } \\
(\%)\end{array}$ & $\begin{array}{l}\text { PL } \\
(\%)\end{array}$ \\
\hline 0 & 0 & 0 & 0 & * & $*$ & $*$ & $*$ & * & $*$ \\
\hline 2 & 4 & 4 & 4 & $*$ & 0,55 & $\begin{array}{c}0,8 \\
3\end{array}$ & $95 \%$ & $\begin{array}{l}55 \\
\%\end{array}$ & $40 \%$ \\
\hline 4 & 6 & 6 & 6 & $*$ & 0,69 & $\begin{array}{c}1,0 \\
3\end{array}$ & $93 \%$ & $\begin{array}{l}53 \\
\%\end{array}$ & $40 \%$ \\
\hline 6 & 9 & 9 & 9 & $*$ & 0,83 & $\begin{array}{c}1,2 \\
5\end{array}$ & $62 \%$ & $\begin{array}{l}31 \\
\%\end{array}$ & $31 \%$ \\
\hline 8 & 8 & 8 & 8 & $*$ & 0,98 & $\begin{array}{c}1,4 \\
8\end{array}$ & $79 \%$ & $\begin{array}{l}43 \\
\%\end{array}$ & $36 \%$ \\
\hline 10 & 9 & 9 & 9 & $*$ & 1,14 & $\begin{array}{c}1,7 \\
0\end{array}$ & $75 \%$ & $\begin{array}{l}40 \\
\%\end{array}$ & $35 \%$ \\
\hline 12 & 9 & 9 & 9 & $*$ & 1,29 & $\begin{array}{c}1,9 \\
4\end{array}$ & $75 \%$ & $\begin{array}{l}40 \\
\%\end{array}$ & $35 \%$ \\
\hline
\end{tabular}

(c)

Perencanaan PVD dilakukan dengan perhitungan menurut Ground Engineering, mengenai PVD untuk mempercepat proses pemampatan tanah dasar [4]. Dari perhitungan PVD dipilih PVD dengan jarak $1 \mathrm{~m}$ untuk STA 414+525 dan PVD jarak 0,8 m untuk STA 424+576 mempertimbangkan lama waktu hingga minimal derajat konsolidasi mencapai 90\%. (Gambar 9)

5. Perhitungan Pemampatan Tanah Dasar Akibat Soil Preloading dan Vacuum Preloading.
Perhitungan besar pemampatan dari persamaan (Noor Endah, 2012) untuk mengetahui grafik hubungan antara waktu dan pemampatan tiap tahap. Variasi timbunan STA 414+525 dapat dilihat pada Gambar 10 dan Gambar 11.

\begin{tabular}{ccccc}
\multicolumn{3}{c}{ Tabel 2. Spesifikasi Material Timbunan } \\
\hline \multirow{2}{*}{ Parameter Timbunan } & \multirow{2}{*}{ Tanah Sirtu } & \multicolumn{2}{c}{ Mortar Busa } \\
& & & Base & Subbase \\
\hline$\gamma$ & $\left(\mathrm{t} / \mathrm{m}^{3}\right)$ & 1,85 & 0,8 & 0,6 \\
$\mathrm{C}$ & $\left(\mathrm{t} / \mathrm{m}^{2}\right)$ & 0 & 0 & 0 \\
$\Phi$ & $\mathrm{o}$ & 30 & 40 & 45 \\
\hline
\end{tabular}

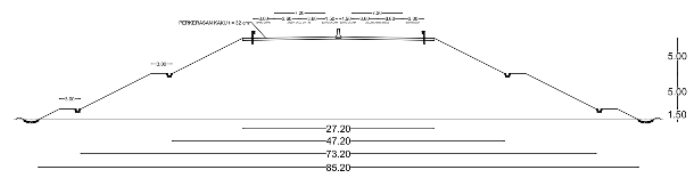

Gambar 5. Cross Section Timbunan Jalan STA 414+525.

Tabel 3. Rekapitulasi Pembebanan Pada Timbunan Tanah Sirtu STA $414+525$

\begin{tabular}{cccccccc}
\hline $\begin{array}{c}\mathrm{H} \\
\text { Timbun } \\
\text { an }\end{array}$ & $\begin{array}{c}\mathrm{q} \\
\text { Timbun } \\
\text { an }\end{array}$ & $\begin{array}{c}\mathrm{H} \\
\text { trapesiu } \\
\mathrm{m} 3\end{array}$ & $\mathrm{~b}$ & $\mathrm{a}$ & $\begin{array}{c}\mathrm{H} \\
\text { trapesiu } \\
\mathrm{m} 2\end{array}$ & $\mathrm{~b}$ & $\mathrm{a}$ \\
$(\mathrm{m})$ & $\left(\mathrm{t} / \mathrm{m}^{2}\right)$ & $(\mathrm{m})$ & $(\mathrm{m})$ & $(\mathrm{m})$ & $(\mathrm{m})$ & $(\mathrm{m})$ & $(\mathrm{m})$ \\
\hline \multirow{2}{*}{10,811} & 20 & 5 & 6 & 0 & 5 & 6 & 0 \\
& & & 13, & 10, & & 26, & 10, \\
11,892 & 22 & 5 & 6 & 0 & 5 & 6 & 0 \\
& & & 13, & 10, & & 26, & 10, \\
12,973 & 24 & 5 & 6 & 0 & 5 & 6 & 0 \\
& & & 13, & 10, & & 26, & 10, \\
14,054 & 26 & 5 & 6 & 0 & 5 & 6 & 0 \\
\hline
\end{tabular}

\begin{tabular}{|c|c|c|c|c|c|c|}
\hline $\begin{array}{c}\mathrm{H} \\
\text { trapesiu } \\
\mathrm{m} 1\end{array}$ & b & a & $\begin{array}{c}\mathrm{H} \\
\text { Pavemen } \\
\mathrm{t}\end{array}$ & $\begin{array}{c}\mathrm{q} \\
\text { Pavemen } \\
\mathrm{t}\end{array}$ & $\begin{array}{c}q \\
\text { Traffi } \\
c\end{array}$ & $\begin{array}{c}\mathrm{H} \\
\text { Bongka } \\
\mathrm{r} \\
\text { Traffic }\end{array}$ \\
\hline (m) & $(\mathrm{m})$ & $\begin{array}{c}(\mathrm{m} \\
\text { ) }\end{array}$ & (m) & $\left(\mathrm{t} / \mathrm{m}^{2}\right)$ & $\left(\mathrm{t} / \mathrm{m}^{2}\right)$ & (m) \\
\hline 0,811 & $\begin{array}{c}39 \\
6 \\
39\end{array}$ & 1,6 & 0,32 & 0,704 & 1,00 & 0,54 \\
\hline 1,892 & $\begin{array}{c}6 \\
39\end{array}$ & 3,8 & 0,32 & 0,704 & 1,00 & 0,54 \\
\hline 2,973 & $\begin{array}{c}6 \\
39\end{array}$ & 5,9 & 0,32 & 0,704 & 1,00 & 0,54 \\
\hline 4,054 & 6 & 8,1 & 0,32 & 0,704 & 1,00 & 0,54 \\
\hline
\end{tabular}

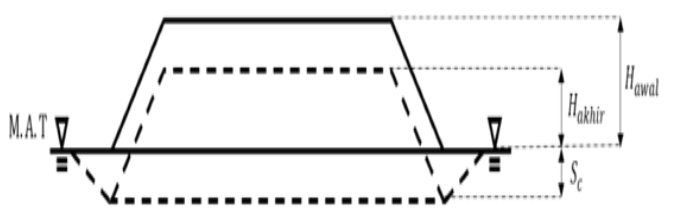

$q=\left(H_{\text {initial }}-S c\right) \times \gamma_{\text {timb }}+S c \times \gamma_{\text {timb }}^{\prime}$

$q=\left(H_{\text {initial }} \times \gamma_{\text {timb }}\right)-\left(S c \times \gamma_{\text {timb }}\right)+\left(S c \times \gamma_{\text {timb }}^{\prime}\right)$

$H_{\text {initial }}=\left(q+\left(S c \times \gamma_{\text {timb }}\right)+\left(S c \times \gamma_{\text {timb }}^{\prime}\right)\right) \gamma_{\text {timb }}$

Gambar 6. Kebutuhan tinggi awal timbunan akibat pemampatan tanah dasar.

Pada variasi timbunan tanah sirtu STA $414+525$ beban pompa vacuum sebesar $8,245 \mathrm{t} / \mathrm{m}^{2}$ dipasang pada tahap ketiga dan setelah mencapai pemampatan rencana pompa vacuum dimatikan yaitu pada minggu ke 13. Jadi pompa vacuum dinyalakan selama 10 minggu, pemampatan yang terjadi lebih cepat, dapat dilihat pada Gambar 11 (b) minggu ke 18 besar pemampatannya sudah sebesar 1,17 m lebih cepat 6 minggu daripada menggunakan soil 
preloading dimana untuk mencapai pemampatan $1,17 \mathrm{~m}$ membutuhkan waktu 24 minggu, dapat dilihat pada Gambar 11 (a)

6. Perencanaan Perkuatan dengan Geotextile

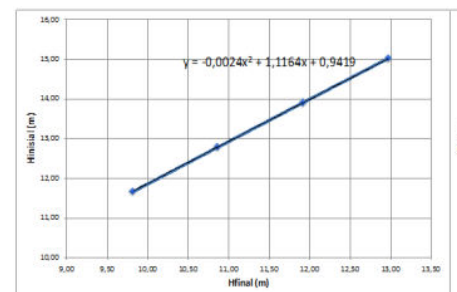

(a)

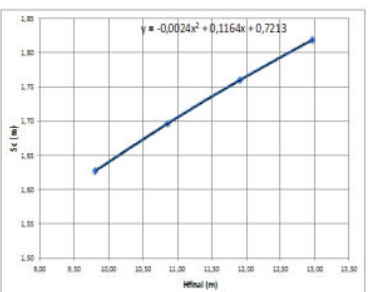

(b)
Gambar 7. (a) Hubungan Antara $\mathrm{H}_{\text {final }}$ dan $\mathrm{H}_{\text {initial }}$ Timbunan Tanah Sirtu STA 414+525 (b) Hubungan Antara Hfinal dan Sc Timbunan Tanah Sirtu STA $414+525$.

Tabel 5. Rekapitulasi Perhitungan Hinitial, Hfinal, dan ScTimbunan 25\% Mortar Busa 75\% Tanah Sirtu STA 414+525P

\begin{tabular}{|c|c|c|c|c|c|c|c|}
\hline $\begin{array}{l}\text { Beb } \\
\text { an q }\end{array}$ & $\begin{array}{c}\text { Sc } \\
\text { Akib } \\
\text { at q }\end{array}$ & $\begin{array}{c}\mathrm{H} \\
\text { initi } \\
\text { al }\end{array}$ & $\begin{array}{c}\text { Sc } \\
\text { Pavem } \\
\text { ent }\end{array}$ & $\begin{array}{c}\text { H } \\
\text { Bong } \\
\text { kar } \\
\text { Traffi } \\
\text { c }\end{array}$ & $\begin{array}{c}\mathrm{H} \\
\text { pavemen } \\
\mathrm{t}\end{array}$ & $\begin{array}{c}\text { Sc } \\
\text { Total }\end{array}$ & $\begin{array}{c}\mathrm{H} \\
\text { final }\end{array}$ \\
\hline$\left(\begin{array}{c}\mathrm{t} / \mathrm{m} \\
\left.{ }^{2}\right)\end{array}\right.$ & (m) & (m) & (m) & (m) & (m) & (m) & (m) \\
\hline \multirow{3}{*}{20} & 1,57 & 17, & \multirow{3}{*}{0,053} & \multirow{3}{*}{0,54} & \multirow{3}{*}{0,32} & \multirow{3}{*}{1,63} & 15,7 \\
\hline & 5 & 58 & & & & & 3 \\
\hline & 1,64 & 19 & & & & & 17,3 \\
\hline \multirow[t]{2}{*}{22} & 5 & 27 & \multirow[t]{2}{*}{0,052} & \multirow[t]{2}{*}{0,54} & \multirow[t]{2}{*}{0,32} & \multirow[t]{2}{*}{1,70} & 5 \\
\hline & 1,70 & 20 & & & & & 18,9 \\
\hline \multirow[t]{2}{*}{24} & 9 & 95 & \multirow[t]{2}{*}{0,051} & \multirow[t]{2}{*}{0,54} & \multirow[t]{2}{*}{0,32} & \multirow[t]{2}{*}{1,76} & 7 \\
\hline & 1,76 & 22 & & & & & 20,6 \\
\hline 26 & 9 & 64 & 0,050 & 0,54 & 0,32 & 1,82 & 0 \\
\hline
\end{tabular}

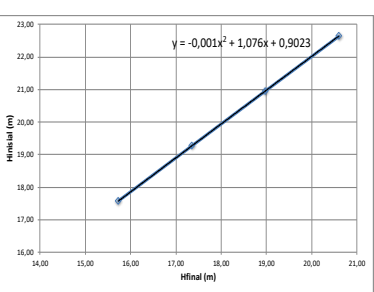

(a)

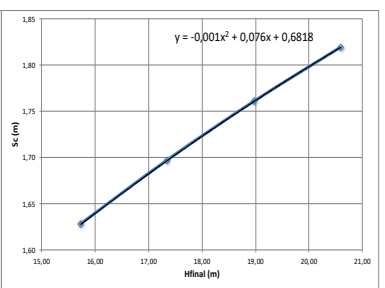

(b)
Gambar 8. (a) Hubungan Antara $\mathrm{H}_{\text {final }}$ dan $\mathrm{H}_{\text {initial }}$ Timbunan $50 \%$ Mortar Busa 50\% Tanah Sirtu STA 414+525 (b) Hubungan Antara Hfinal dan Sc Timbunan 50\% Mortar Busa 50\% Tanah Sirtu STA $414+525$.

Tabel 6. Rekapitulasi Nilai Hinitial dan Stotal STA 414+525

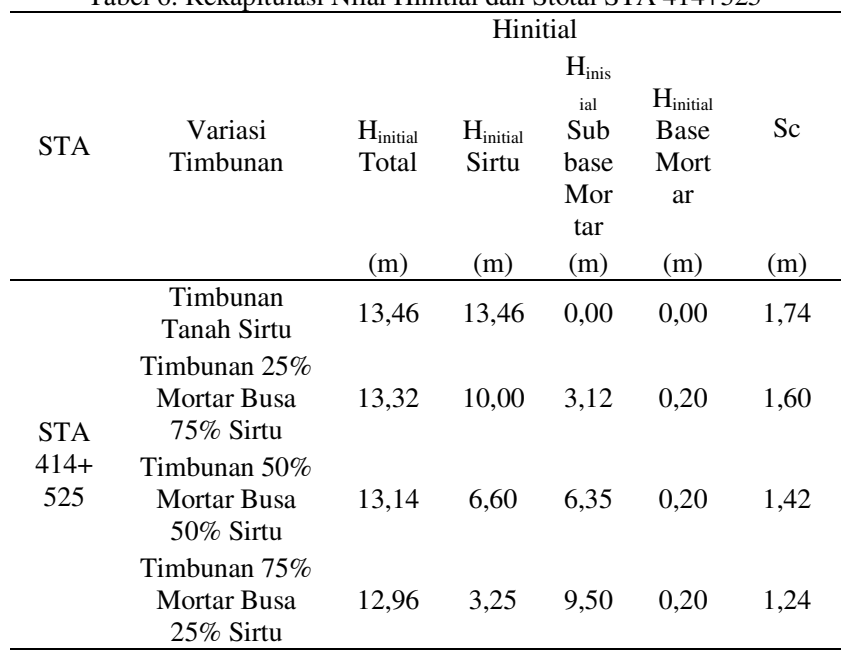

Perencanaan perkuatan dengan geotextile dilakukan pada timbunan di STA yang memiliki nilai SF di bawah $\mathrm{SF}_{\text {rencana }}=1,2$, untuk perhitungan jumlah kebutuhan geotextile, nilai SF dicari sebanyak beberapa kali dengan program bantu Xstabl untuk kondisi Internal Stability (Table 8).

Harus diperhatikan bahwa setiap geotextile yang dipasang jumlah total dari $\mathrm{M}_{\text {geotextile }}\left(\Sigma \mathrm{M}_{\text {geotextile }}\right)$ harus lebih besar dari $\Delta M R\left(\Sigma \mathrm{M}_{\text {geotextile }} \geq \Delta M R\right)$.

Tabel 7. Rate Of Settlement Di Bawah Timbunan Tanah Sirtu

\begin{tabular}{cccc}
\multicolumn{4}{c}{ STA 414+525 } \\
\hline $\begin{array}{c}\text { Derajat } \\
\text { Konsolidasi }\end{array}$ & Faktor Waktu & Tahun & Pemampatan \\
$\mathrm{U}(\%)$ & $\mathrm{Tv}$ & $\mathrm{t}$ (Tahun) & $\mathrm{Sc}(\mathrm{m})$ \\
\hline 0,00 & 0,000 & 0,00 & 0,00 \\
10,00 & 0,008 & 1,03 & 0,17 \\
20,00 & 0,031 & 4,13 & 0,35 \\
30,00 & 0,071 & 9,30 & 0,52 \\
40,00 & 0,126 & 16,53 & 0,70 \\
50,00 & 0,196 & 25,83 & 0,87 \\
60,00 & 0,283 & 37,20 & 1,05 \\
70,00 & 0,403 & 53,00 & 1,22 \\
80,00 & 0,567 & 74,61 & 1,39 \\
90,00 & 0,848 & 111,56 & 1,57 \\
\hline
\end{tabular}

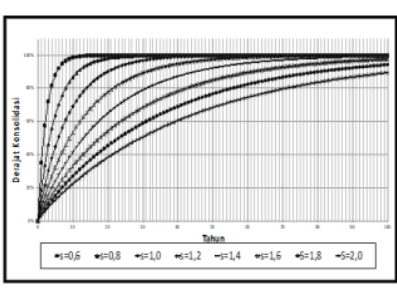

(a)

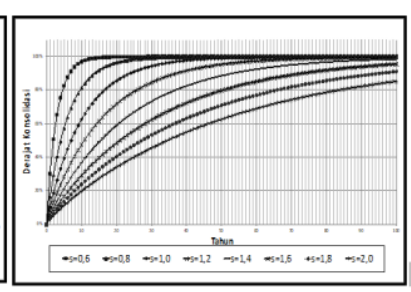

(b)
Gambar 9. Hubungan Antara Derajat Konsolidasi (U) dan Waktu (t) Pada PVD (a) Pola Segitiga (b) Pola Segiempat.

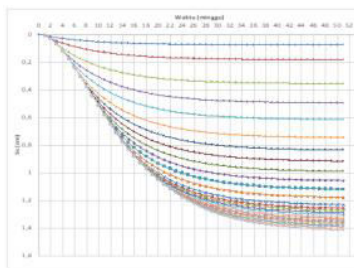

(a)

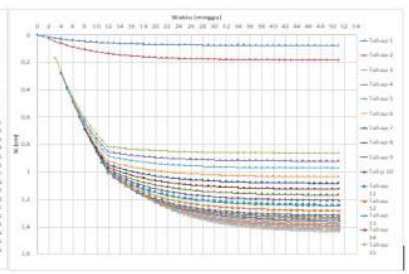

(b)
Gambar 11. Hubungan Antara Nilai Pemampatan (s) dan Waktu Pentahapan (t) Untuk timbunan 50\% mortar busa 50\% tanah sirtu STA $414+525$ (a) Soil Preloading (b) Vacuum Preloading.

\begin{tabular}{cccccc}
\multicolumn{5}{c}{ Tabel 8. Hasil Analisa dari Program Bantu Xstabl } \\
\hline \multirow{5}{*}{ No } & SF & \multicolumn{3}{c}{ Circle Center } \\
Coord. & Radius & MR \\
& (BISHOP) & x (m) & y $(\mathrm{m})$ & $(\mathrm{m})$ & $(\mathrm{kNm})$ \\
\hline 1 & 0,995 & 58,80 & 42,58 & 30,63 & 63290 \\
2 & 1,000 & 58,97 & 43,41 & 31,32 & 65710 \\
3 & 1,003 & 57,54 & 44,44 & 33,01 & 71850 \\
4 & 1,006 & 57,03 & 46,79 & 36,27 & 86580 \\
5 & 1,006 & 56,38 & 48,48 & 38,97 & 100300 \\
6 & 1,006 & 56,43 & 48,57 & 39,08 & 100900 \\
7 & 1,010 & 60,77 & 41,80 & 29,51 & 61770 \\
8 & 1,011 & 54,94 & 50,09 & 41,05 & 10830 \\
9 & 1,012 & 57,38 & 46,63 & 34,42 & 74030 \\
10 & 1,013 & 59,67 & 41,03 & 28,18 & 54520 \\
\hline
\end{tabular}

7. Perhitungan Biaya Material (Tabel 10-12)

Dari Tabel 10, Tabel 11 dan Tabel 12 didapatkan biaya total paling kecil pada timbunan menggunakan material Tanah Sirtu, Contohnya pada STA 414+525 variasi timbunan tanah sirtu sebesar Rp14.922.116.023,00 , tetapi kebutuhan geotextile sebesar Rp4.671.855.000,00 dan PVD sebesar Rp425.305.499,00 membutuhkan biaya paling besar dari Variasi timbunan yang lain. Biaya tambahan untuk mempercepat waktu dengan vacuum preloading pada variasi tanah sirtu sebesar Rp126.432.000,00. 


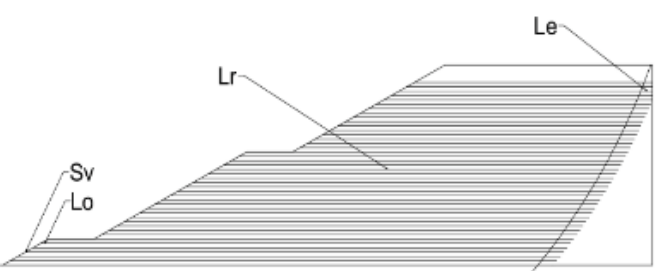

Gambar 12. Perencanaan Pemasangan Geotextile pada Variasi Timbunan Tanah Sirtu STA 414+525.

\begin{tabular}{ccccc}
\multicolumn{5}{c}{ Tabel 8. Hasil Analisa dari Program Bantu Xstabl (lanjutan) } \\
\hline \multirow{2}{*}{ No } & $\begin{array}{c}\text { SF } \\
\text { Rencana }\end{array}$ & M dorong & $\begin{array}{c}\mathrm{MR} \\
\text { rencana } \\
\mathrm{kNm}\end{array}$ & $\Delta \mathrm{MR}$ \\
& & $\mathrm{kNm}$ & $\mathrm{kNm}$ \\
\hline 1 & 1,2 & 63608,04 & 76329,65 & 13039,65 \\
2 & 1,2 & 65710,00 & 78852,00 & 13142,00 \\
3 & 1,2 & 71635,09 & 85962,11 & 14112,11 \\
4 & 1,2 & 86063,62 & 103276,34 & 16696,34 \\
5 & 1,2 & 99701,79 & 119642,15 & 19342,15 \\
6 & 1,2 & 100298,21 & 120357,85 & 19457,85 \\
7 & 1,2 & 61158,42 & 73390,10 & 11620,10 \\
8 & 1,2 & 10712,17 & 12854,60 & 2024,60 \\
9 & 1,2 & 73152,17 & 87782,61 & 13752,61 \\
10 & 1,2 & 53820,34 & 64584,40 & 10064,40 \\
\hline
\end{tabular}

Tabel 9 Perhitungan Kebutuhan Jumlah Geotextile Timbunan Tanah Sirtu STA 414+525

\begin{tabular}{ccccc}
\hline \multirow{2}{*}{ Lapis } & $\begin{array}{c}\text { Sv } \\
\mathrm{m}\end{array}$ & $\begin{array}{c}\text { Lo } \\
\mathrm{m}\end{array}$ & $\begin{array}{c}\text { Le }+ \text { Lr }(\mathrm{m}) \\
\text { satu sisi }\end{array}$ & $\begin{array}{c}1 / 2 \text { Lebar Timbunan } \\
\mathrm{m}\end{array}$ \\
\hline 1 & 0,25 & 1,00 & 36,10 & 42,6 \\
2 & 0,25 & 1,00 & 35,90 & 42,1 \\
3 & 0,25 & 1,00 & 35,60 & 41,6 \\
4 & 0,25 & 1,00 & 35,30 & 41,1 \\
5 & 0,25 & 1,00 & 35,00 & 40,6 \\
6 & 0,25 & 1,00 & 34,70 & 40,1 \\
7 & 0,25 & 1,00 & 31,50 & 36,6 \\
8 & 0,25 & 1,00 & 31,20 & 36,1 \\
$\ldots$ & $\ldots \ldots$ & $\ldots$ & $\ldots \ldots$ & 17,6 \\
39 & 0,25 & 1,00 & 17,60 & 17,1 \\
40 & 0,25 & 1,00 & 17,30 & 16,6 \\
41 & 0,25 & 1,00 & 16,90 & 16,1 \\
42 & 0,25 & 1,00 & 16,50 & 15,6 \\
43 & 0,25 & 1,00 & 16,20 &
\end{tabular}

Tabel 9 Perhitungan Kebutuhan Jumlah Geotextile Timbunan Tanah Sirtu STA 414+525 (lanjutan)

\begin{tabular}{|c|c|c|c|c|}
\hline Lapis & Pemasangan & $\begin{array}{c}\mathrm{L} \\
\text { pemasangan } \\
\mathrm{m}\end{array}$ & $\begin{array}{c}\text { Jumlah } \\
\text { Geotextile }\end{array}$ & $\begin{array}{c}\text { Kebutuhan } \\
\text { Geotextile } \\
\text { Total (m) }\end{array}$ \\
\hline 1 & Dua kali L total & 74,70 & 2 & 149,4 \\
\hline 2 & Dua kali L total & 74,30 & 2 & 148,6 \\
\hline 3 & Dua kali L total & 73,70 & 2 & 147,4 \\
\hline 4 & Dua kali L total & 73,10 & 2 & 146,2 \\
\hline 5 & Dua kali L total & 72,50 & 2 & 145,0 \\
\hline 6 & Dua kali L total & 71,90 & 2 & 143,8 \\
\hline 7 & Dua kali L total & 65,50 & 2 & 131,0 \\
\hline 8 & Dua kali L total & 64,90 & 2 & 129,8 \\
\hline$\ldots$ & $\ldots$ & $\ldots$ & $\ldots$ & . \\
\hline 39 & Dua kali L total & 37,70 & 1 & 37,7 \\
\hline 40 & Selebar Timbunan & 36,70 & 1 & 36,7 \\
\hline 41 & Selebar Timbunan & 35,70 & 1 & 35,7 \\
\hline 42 & Selebar Timbunan & 34,70 & 1 & 34,7 \\
\hline 43 & Selebar Timbunan & 33,70 & 1 & 33,7 \\
\hline & & \multicolumn{2}{|c|}{ Jumlah Geotextile } & 2955,0 \\
\hline
\end{tabular}

Tabel 10. Rekapitulasi Biaya Material Geoteknik pada Variasi Timbunan STA 414+525

\begin{tabular}{ccc}
\hline Variasi Timbunan & $\begin{array}{c}\text { Biaya Meterial } \\
\text { Timbunan }\end{array}$ & Biaya Material PVD \\
\hline Timbunan Tanah Sirtu & Rp14.922.116.023 & Rp425.305.499 \\
$\begin{array}{c}\text { Timbunan 25\% Mortar } \\
\text { Busa 75\% Sirtu }\end{array}$ & Rp20.955.229.231 & Rp422.613.576 \\
Timbunan 50\% Mortar & Rp29.015.304.610 & Rp419.440.985 \\
Busa 50\% Sirtu & Rp40.119.263.731 & Rp416.119.047
\end{tabular}

Busa $25 \%$ Sirtu

Timbunan Tanah Sirtu

Timbunan 25\% Mortar Busa $75 \%$ Sirtu

Timbunan 50\% Mortar Busa $50 \%$ Sirtu

Timbunan $75 \%$ Mortar Busa $25 \%$ Sirtu

\begin{tabular}{|c|c|}
\hline Rp 4.671.855.000 & Rp 274.914.000 \\
\hline Rp 3.038.682.000 & Rp 273.159.000 \\
\hline Rp 916.980.000 & Rp 271.134.000 \\
\hline $\operatorname{Rp} 0$ & $\operatorname{Rp} 269.001 .000$ \\
\hline $\operatorname{nan}$ & Total Biaya \\
\hline Sirtu & Rp20.294.190.523 \\
\hline usa $75 \%$ Sirtu & Rp24.689.683.807 \\
\hline usa $50 \%$ Sirtu & Rp30.622.859.595 \\
\hline usa $25 \%$ Sirtu & Rp40.804.383.777 \\
\hline
\end{tabular}

Timbunan 50\% Mortar Busa 50\% Sirtu Timbunan $75 \%$ Mortar Busa 25\% Sirtu Rp40.804.383.777

Tabel 11. Rekapitulasi Biaya Material Geoteknik pada Variasi Timbunan STA 414+525 Menggunakan Vacuum Preloading

\begin{tabular}{ccc}
\hline Variasi Timbunan & $\begin{array}{c}\text { Biaya Meterial } \\
\text { Timbunan }\end{array}$ & $\begin{array}{c}\text { Biaya Material } \\
\text { PVD }\end{array}$ \\
\hline Timbunan Tanah Sirtu & Rp14.922.116.023 & Rp425.305.499 \\
Timbunan 25\% Mortar & Rp20.955.229.231 & Rp422.613.576 \\
Busa 75\% Sirtu & & \\
$\begin{array}{c}\text { Timbunan 50\% Mortar } \\
\text { Busa 50\% Sirtu }\end{array}$ & Rp29.015.304.610 & Rp419.440.985 \\
$\begin{array}{c}\text { Timbunan 75\% Mortar } \\
\text { Busa 25\% Sirtu }\end{array}$ & Rp40.119.263.731 & Rp416.119.047 \\
\hline
\end{tabular}

Tabel 11. Rekapitulasi Biaya Material Geoteknik pada Variasi Timbunan STA 414+525 Menggunakan Vacuum Preloading (lanjutan)

\begin{tabular}{ccc}
\hline Variasi Timbunan & $\begin{array}{c}\text { Biaya Material } \\
\text { Geotextile }\end{array}$ & $\begin{array}{c}\text { Total Biaya } \\
\text { PHD }\end{array}$ \\
\hline Timbunan Tanah Sirtu & Rp4.671.855.000 & Rp274.914.000 \\
$\begin{array}{c}\text { Timbunan 25\% Mortar } \\
\text { Busa 75\% Sirtu }\end{array}$ & Rp3.038.682.000 & Rp273.159.000 \\
$\begin{array}{c}\text { Timbunan 50\% Mortar } \\
\text { Busa 50\% Sirtu }\end{array}$ & Rp916.980.000 & Rp271.134.000 \\
$\begin{array}{c}\text { Timbunan 75\% Mortar } \\
\text { Busa 25\% Sirtu }\end{array}$ & Rp0 & Rp269.001.000 \\
\hline
\end{tabular}

Tabel 11. Rekapitulasi Biaya Material Geoteknik pada Variasi Timbunan STA 414+525 Menggunakan Vacuum Preloading (lanjutan)

\begin{tabular}{cc}
\hline Variasi Timbunan & $\begin{array}{c}\text { Biaya Pompa } \\
\text { Vacuum }\end{array}$ \\
\hline Timbunan Tanah Sirtu & Rp126.432.000 \\
Timbunan 25\% Mortar Busa 75\% Sirtu & Rp124.632.000 \\
Timbunan 50\% Mortar Busa 50\% Sirtu & Rp122.832.000 \\
Timbunan 75\% Mortar Busa 25\% Sirtu & Rp121.032.000 \\
\hline
\end{tabular}

Tabel 11. Rekapitulasi Biaya Material Geoteknik pada Variasi Timbunan STA 414+525 Menggunakan Vacuum Preloading (lanjutan) Variasi Timbunan Biaya Meterial Timbunan Timbunan Tanah Sirtu Rp20.420.622.523

Timbunan 25\% Mortar Busa 75\% Sirtu Rp24.814.315.807

Timbunan 50\% Mortar Busa 50\% Sirtu Rp30.745.691.595 Timbunan 75\% Mortar Busa 25\% Sirtu Rp40.925.415.777

Tabel 12. Rekapitulasi Biaya Material Geoteknik pada Variasi Timbunan STA 424+576

\begin{tabular}{|c|c|c|}
\hline Variasi Timbunan & $\begin{array}{l}\text { Biaya Meterial } \\
\text { Timbunan }\end{array}$ & $\begin{array}{l}\text { Biaya Material } \\
\text { PVD }\end{array}$ \\
\hline Timbunan Tanah Sirtu & Rp5.952.630.436 & Rp520.825.584 \\
\hline $\begin{array}{c}\text { Timbunan } 25 \% \text { Mortar Busa } \\
75 \% \text { Sirtu }\end{array}$ & Rp9.281.278.259 & Rp514.809.024 \\
\hline $\begin{array}{c}\text { Timbunan } 50 \% \text { Mortar Busa } \\
50 \% \text { Sirtu }\end{array}$ & Rp12.747.419.227 & Rp507.630.624 \\
\hline $\begin{array}{c}\text { Timbunan } 75 \% \text { Mortar Busa } \\
25 \% \text { Sirtu }\end{array}$ & Rp16.224.391.113 & Rp499.814.112 \\
\hline
\end{tabular}

Tabel 12. Rekapitulasi Biaya Material Geoteknik pada Variasi Timbunan STA 424+576 (lanjutan)

\begin{tabular}{|c|c|c|}
\hline Variasi Timbunan & $\begin{array}{l}\text { Biaya Material } \\
\text { Geotextile }\end{array}$ & $\begin{array}{c}\text { Biaya Material } \\
\text { PVD }\end{array}$ \\
\hline Timbunan Tanah Sirtu & Rp0 & Rp338.688.000 \\
\hline $\begin{array}{c}\text { Timbunan } 25 \% \text { Mortar Busa } \\
75 \% \text { Sirtu }\end{array}$ & Rp0 & Rp334.827.000 \\
\hline $\begin{array}{c}\text { Timbunan 50\% Mortar Busa } \\
50 \% \text { Sirtu }\end{array}$ & Rp0 & Rp330.210.000 \\
\hline $\begin{array}{c}\text { Timbunan } 75 \% \text { Mortar Busa } \\
25 \% \text { Sirtu }\end{array}$ & Rp0 & Rp325.188.000 \\
\hline
\end{tabular}


Tabel 12. Rekapitulasi Biaya Material Geoteknik pada Variasi

\begin{tabular}{cc}
\multicolumn{2}{c}{ Timbunan STA 424+576 (lanjutan) } \\
\hline Variasi Timbunan & Total Biaya \\
\hline Timbunan Tanah Sirtu & Rp6.812.144.020 \\
Timbunan 25\% Mortar Busa 75\% Sirtu & Rp10.130.914.283 \\
Timbunan 50\% Mortar Busa 50\% Sirtu & Rp13.585.259.851 \\
Timbunan 75\% Mortar Busa 25\% Sirtu & Rp17.049.393.225 \\
\hline
\end{tabular}

\section{KESIMPULAN}

1. Dengan perhitungan preloading akibat beban $\mathrm{q}$, didapatkan timbunan dengan variasi mortar busa memiliki nilai $\mathrm{H}_{\text {intial }}$ lebih kecil daripada timbunan tanah sirtu dengan nilai $\mathrm{H}_{\text {final }}$ sama.

2. Timbunan mortar busa memiliki berat jenis yang lebih ringan daripada timbunan tanah sirtu, dari hasil perhitungan nilai pemampatan (Sc) pada timbunan mortar busa lebih kecil daripada timbunan tanah sirtu.

3. Timbunan mortar busa cenderung memiliki stabilitas yang lebih tinggi karena memiliki nilai Safety Factor (SF) yang lebih tinggi dari timbunan tanah sirtu. Kebutuhan perkuatan tanah dengan geotextile membutuhkan jumlah lebih sedikit dan lama waktu untuk pelaksanaan penimbunan dengan penggunaan PVD maupun vacuum preloading lebih cepat daripada timbunan tanah sirtu.

4. Berdasarkan perhitungan waktu dan biaya material geoteknik yang telah dilakukan antara variasi timbunan dengan material tanah sirtu dan material mortar busa, dapat diketahui bahwa :

a. Timbunan dengan material mortar busa memiliki harga material jauh lebih mahal daripada tanah sirtu.

b. Biaya akan perkuatan timbunan dengan variasi material mortar busa memerlukan geotextile lebih kecil dan cenderung tidak memerlukan perkuatan karena nilai $\mathrm{SF}$ lebih tinggi dari $\mathrm{SF}_{\text {rencana }}$

c. Timbunan dengan variasi mortar busa memiliki waktu penimbunan yang lebih cepat daripada hanya menggunakan timbunan tanah sirtu karena memiliki $\mathrm{h}_{\text {intial }}$ dan nilai Sc yang lebih kecil.

d. Penggunaan vacuum preloading mempercepat pemampatan yang terjadi sekitar 4-7 minggu pada variasi timbunan STA $414+525$ tetapi ada biaya tambahan untuk pompa vacuum dan biaya operasional.

Dari hasil analisa yang sudah dilakukan timbunan tanah sirtu menjadi alternatif yang paling ekonomis dan variasi timbunan $75 \%$ mortar busa $25 \%$ tanah sirtu menjadi alternatif timbunan dengan stabilitas yang paling tinggi, apabila mempertimbangkan biaya dan stabilitas dapat menggunakan alternatif $25 \%$ mortar busa $75 \%$ tanah sirtu.

Saran

1. Jika ingin melakukan perencanaan timbunan jalan tol dengan memakai material ringan mortar busa, sebaiknya perlu diperhatikan faktor dana yang dimiliki karena walaupun timbunan dengan material mortar busa lebih stabil, harga materialnya jauh lebih mahal daripada material tanah sirtu.

2. Sebaiknya pemilihan perencanaan timbunan jalan tol dengan memakai material ringan mortar busa digunakan apabila di lokasi proyek sulit untuk mendatangkan material sirtu maka dapat di alternatifkan menggunakan material mortar busa.

3. Alangkah baiknya perlu dilakukan studi lebih lanjut mengenai optimasi harga serta penggunaan material mortar busa di berbagai jenis proyek dan lokasi.

\section{DAFTAR PUSTAKA}

[1] M. Das, Mekanika Tanah (Prinsip-prinsip Rekayasa Geoteknis). Jakarta: Erlangga, 1995.

[2] I. B. Mochtar, Teknologi Perbaikan Tanah dan Alternatif Perencanaan pada Tanah Bermasalah (Problematic Soils). Surabaya, 2000.

[3] M. Iqbal, "Kajian Penanganan Tanah Lunak Dengan Timbunan Jalan Mortar Busa - PDF," 2012. [Online]. Available: http://docplayer.info/79044475-Kajian-penanganan-tanah-lunakdengan-timbunan-jalan-mortar-busa.html. [Accessed: 20-Mar2019].

[4] Sven Hansbo, "Consolidation Of Clay By Band-Shaped Prefabricated Drains.," Gr. Eng., vol. 12, no. 5, pp. 21-25, 1979. 